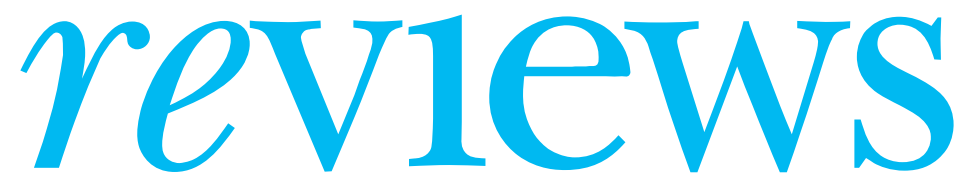

BOOKS • CD ROMS • ART •WEBSITES $\bullet$ MEDIA $\bullet$ PERSONAL VIEWS $\bullet$ SOUNDINGS

\section{Harvey Cushing: A Life in Surgery \\ Michael Bliss}

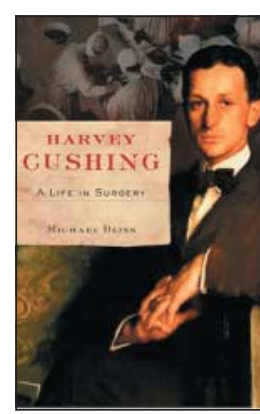

Oxford University Press, $£ 23.99 / \$ 40$, pp 608 ISBN 0195169891 Rating: $\star \star \star \star$

$\mathrm{F}$ or decades professional medical historians considered the biography to be outdated as a genre. However, in recent years there has been a revival of interest in the lives of outstanding individuals. Michael Bliss, a professor of history at the University of Toronto, first published William Osler: A Life in Medicine (review BMJ 2000;321:1087). He sees a Cushing biography as a sequel to the Osler biography: "Each would stand alone, but together the two volumes would be a biographical study of the rise of North American medicine and surgery."

Bliss's biography of Cushing revolves around several metaphors. There are numerous references to sport. Neurosurgery is a team game, and Cushing is compared to a "star player, star coach, and general manager, all in one.” Every operation was like a championship set: "He played tennis the way he operated, and he operated the way he played tennis." Cushing described the first world war as a football game and life in general as a sports event ("Life all round is a kind of sporting event and the best any of us can do is to try continually to improve our game," he wrote to his son Bill). He gave up his surgical practice after hitting a record number of 2000 removed brain tumours. Cushing at the end of his career is likened to an ageing athlete who "collapsed like an exhausted runner."

Bliss notes that "the rise of American medicine in general and neurosurgery in particular was a product of American Puritanism, American democracy, and American wealth." He views Cushing's life as an example of applied Puritanism: "Cushing had been the puritan as perfectionist

Items reviewed are rated on a 4 star scale (4=excellent) surgeon-no germs, no bleeding, no sloppiness, no shortcuts." Cushing called himself "merely a handicraftsman" and privately deprecated surgical contemporaries who pretended to be philosophers.

God-like Cushing was the creator of neurosurgery, Bliss claims. He indeed had a great impact on shaping the specialty, and trained many surgeons from North America and western Europe. The results of his brain tumour surgery were considered a gold standard throughout the world, and he founded the Society of Neurological Surgeons. But Cushing was not the only one to practise neurosurgery in the first decades of the 20th century. Other names include Charles Frazier and Ernest Sachs from the United States, Fedor Krause and Otfrid Foerster from Germany, Antoine Chipault from France, and Ludwig Pussep from Russia.

Bliss admits that "Cushing had been a surgical innovator without being particularly inventive." Most instruments and techniques he used were initially suggested by others. These include monitoring blood pressure with an inflatable cuff invented by Scipione Riva-Rocci, electrosuction introduced by Fedor Krause in 1908 and later adapted by Cushing, and electrocoagulation developed by W T Bovie in the 1920s. H Schloffer used the transsphenoidal approach to pituitary tumours in 1907, two years before Cushing.

Cushing was remarkably prolific at his writing desk, as well as in the operating room. It has been estimated that in the 1920s he committed to paper between 5000 and 10000 words a day, assisted by several female secretaries, typists, stenographers, medical artists, and photographers, called "Cushing's harem." His total literary output comprises 13 books and 330 scientific articles. The recipient of 23 honorary degrees, an honorary member of 60 scientific societies, and the author of 16 prize lectures, Cushing was named in 1931 by William Welch as "the most influential man in the medical world today." In 1939 the New England Journal of Medicine labelled him as "perhaps the foremost physician produced in the United States."

But what was the quality of Cushing's research? According to Walter Dandy (Cushing's former resident at Johns Hopkins), he "was not a real scientist. All of his physiological efforts failed miserably because he tried to prove what he preconceived and he preconceived badly ..." Was Dandy perhaps wrong? Bliss does not produce any evidence in Cushing's support.

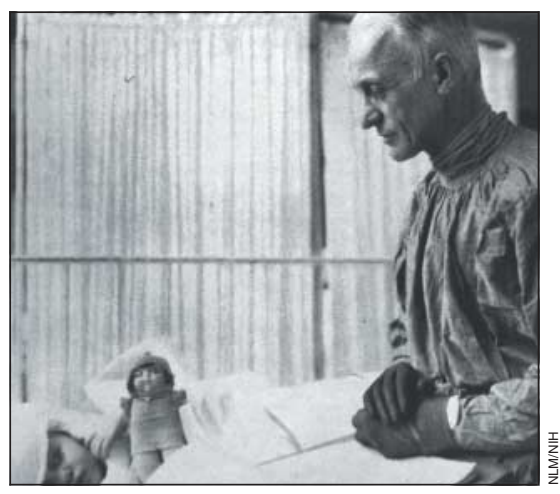

Cushing was devoted to patients, but sadistic to his residents

Much of the book presents a Jekyll and Hyde personality, "hustling Harvey," as Grace Osler nicknamed Cushing. He was charming and selfish, sentimental and racist, devoted to patients and sadistic to his residents, archVictorian in his cultural habits and ultramodern in clinical practice, and addicted to work and tobacco. Cushing was ruthless in his pursuit of knowledge. He "did not use consent forms either for operation or for autopsies." When a patient's relatives refused permission for an autopsy, Cushing would offer them money from his own pocket. Otherwise he would bribe a priest or an undertaker to allow the clandestine removal of postmortem specimens by one of his residents.

Money was not an issue for Cushing. His hospital salary was insufficient to cover the wages of his personal staff. The Cushings' annual income $(\$ 50000$, which is roughly equivalent to $\$ 750000 \quad(£ 396000$; $€ 582000)$ in current purchasing power) mostly came from their parents' estates and trust funds. Patients of moderate means were asked to pay the equivalent of their monthly income. Fees for physicians and their families were waived.

Bliss's book is aimed at a lay audience. It is clearly written, but the author should have gained some minimal knowledge of human anatomy. That might have prevented him referring to the spinal column as "the body's main nerve canal" or describing the cerebellopontine angle as a place "where cerebellum meets the pons at the upper end of the spinal cord." According to Bliss, the pituitary gland is "a little nut of an organ, weighing about half of a gram." In reality, it is three times heavier. Despite these minor criticisms this is an excellent book.

Boleslav Lichterman Centre for the History of Medicine, Moscow, Russia

licht@aha.ru 


\section{Why are so many people dying on Everest?}

I

$\mathrm{t}$ used to be thought that it would be physiologically impossible to climb In 1953 Hillary and Tenzing proved that it was possible to reach the summit with oxygen and in 1978 Messner and Habeler demonstrated it was possible without oxygen. Although Everest has not changed, we now have a better understanding of acclimatisation, improved climbing equipment, and established routes with fixed lines guiding climbers up to the summit. For those climbing with oxygen, the cylinders are much lighter.

It would therefore seem logical that climbing Everest might have become an altogether less deadly activity. However, this year the unofficial body count on Mount Everest has reached 15, the most since the disaster of 1996 when 16 people died, eight in one night following an unexpected storm. An analysis of the death rate on Mount Everest between 1980 and 2002 found it had not changed over the years, with about one death for every 10 successful ascents. A sobering statistic for anyone who reaches the summit is that you have approximately a 1 in 20 chance of not making it down again. So why are there so many people dying on Mount Everest? And more importantly, can we reduce this number?

The main reasons for people dying while climbing Mount Everest are injuries and exhaustion. However, there is also a large proportion of climbers who die from altitude related illness, specifically from high altitude cerebral oedema (HACE) and high altitude pulmonary oedema (HAPE). Usually the cause of death is confirmed by a fellow climber and therefore not entirely accurate, and it is likely that altitude illness may also have contributed to deaths attributed to injuries and exhaustion. him. above 8300 metres is going to be like. Mount Everest with or without oxygen.

This year I was on the north side of Everest as the doctor on the Everestmax expedition (www.everestmax.com). I was shocked by both the amount of altitude related illness and the relative lack of knowledge among people attempting Everest Within my own expedition of only 15 people, there were two cases of high altitude pulmonary oedema and one case of high altitude cerebral oedema, which is far higher than the 1-3\% incidence predicted. Fortunately all these people made a full recovery.

On our summit attempt we were able to help someone with high altitude pulmonary oedema at 7000 metres, but higher up the mountain we passed four bodies of climbers who had been less fortunate. The last body we encountered was of a Frenchman who had reached the summit four days earlier but was too exhausted to descend. His best friend had tried in vain to get him down the mountain, but they had descended only 50 metres in six hours and he had to abandon

Some people believe that part of the reason for the increase in deaths is the number of inexperienced climbers, who pay large sums of money to ascend Everest. However, all the climbers whom I know of who died this year had 8000 metres' climbing experience. In my view, climbers are not climbing beyond their ability but instead beyond their altitude ability. Unfortunately it is difficult to get experience of what it is like climbing above Camp $3(8300$ metres) without climbing Everest. Climbers invariably do not know what their ability

With cerebral oedema you get an altered sense of reality. This is exemplified by Lincoln Hall, a climber attempting Everest this year, who developed high altitude cerebral oedema on the way down from the

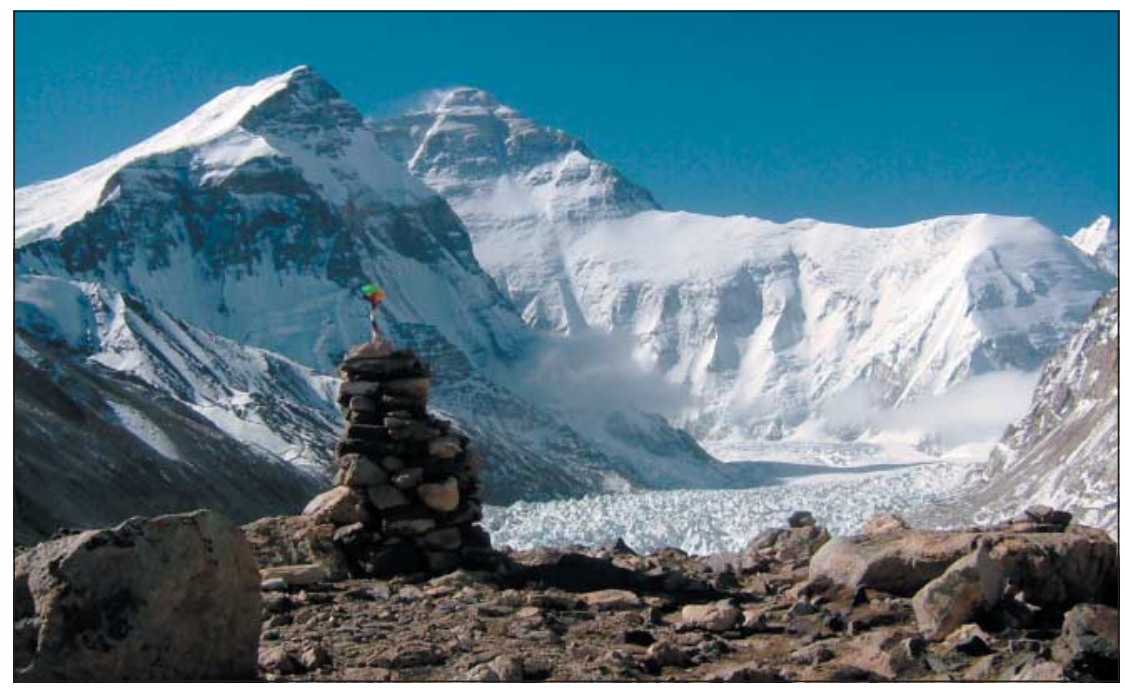

Climbers need to think less about "the climb" and more about their health on the way up Everest

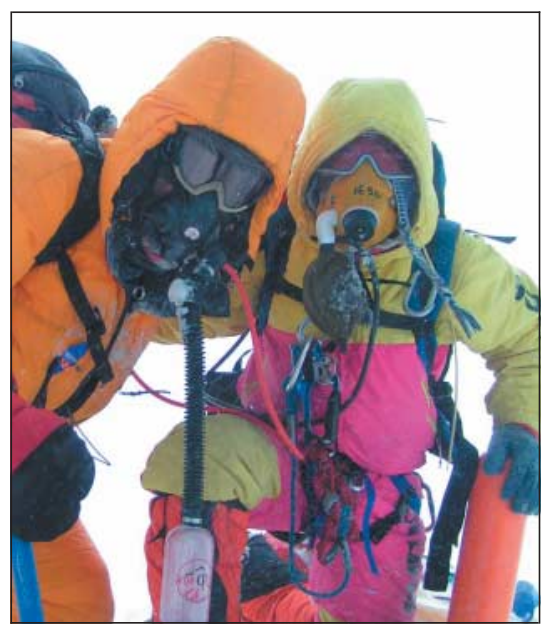

On top of the world: author Andrew Sutherland (left) and Sherpa Tshering at the summit

summit. After being left for dead he was found by another group of climbers the following day. He believed that he was on a sailing boat. At another point he even got on the radio and started coordinating the rescue, oblivious to the fact that the rescue was actually for him.

Is it a milder form of this disorientation that allows climbers to deceive themselves that they can still get to the top and down again? I think it is likely that we all develop a certain degree of pulmonary and cerebral oedema when going to the summit and that it is only a matter of time before we succumb to it. Climbers need to think less about "the climb" and more about their health on the way up. No matter what the affliction, whether it be HACE, HAPE, or just exhaustion, the result is invariably the same-the climber starts to climb more slowly. In general your rate of ascent should be no longer than 1-1.5 hours per 100 metres. If you are too slow this means that something is wrong and your chances of not making it off the mountain are greatly increased. However, with the summit in sight this advice is too often ignored.

When I had to visit the French consulate in Kathmandu to confirm the Frenchman's death, the consul, not a climbing or an altitude expert that I know of, shook his head and said, "He didn't reach the summit until 12.30; that is a 14 hour climb-it is too long. All the files we get of those that die on the mountain, c'est toujour la même chose [it's always the same thing]-they take too long to reach the summit."

Andrew I Sutherland Wellcome research training fellow, Nuffield Department of Surgery, Oxford andrew.sutherland@nds.ox.ac.uk 


\section{Between Chicken Little and the four horsemen of the apocalypse}

$\mathrm{A}$

$t$ a medical meeting in the United States this year, a presentation on avian influenza started with two slides of cartoon drawings, the first, of the feckless Chicken Little of "the sky is falling" fame, and the second, of the four horsemen of the apocalypse. As a local health officer, I feel as if these two images represent the poles of my despair over public health emergency planning.

Tension exists in public health between the rise of public health emergency planning, and our irresistible draw to focus on the real public health problems we face every day. With resources always limited, how do we balance disaster planning with necessary attention to ongoing problems of tobacco, obesity, HIV, maternal/child health, environmental health, and the like? Particularly given the US smallpox vaccination debacle of 2002, we must proceed carefully if we are to sustain our reputation for integrity. I do not wish to be remembered as the official who built this generation's public health equivalent of the Maginot line.

Westchester County, New York, where I work, has a population of 940000 , living on 450 square miles north of New York City. Westchester is one of the most affluent counties in the United States, although nearly one in five Westchester households has an annual income of less than \$25000 (£13 273; €19 483) and nearly one in five children lives below the federal poverty level. The county administration is forward looking, with a genuine concern for public health.

Nevertheless, the budget of the county health department from all sources dropped $5 \%$ from $\$ 33.1 \mathrm{~m}$ in 2002 to $\$ 31.5 \mathrm{~m}$ in 2006 , entailing a reduction in staff of $15 \%$, from 440 to 372 full time equivalent positions. During the same period, Westchester received over $\$ 5 \mathrm{~m}$ in federal bioterrorism funding. Meanwhile, the county has among the highest rates of HIV and AIDS statewide. Clearly, we experience extreme contrasts of wealth and poverty and profound existing public health problems in the face of significant spending for bioterrorism preparedness.

Here is how I have resolved this tension for myself. I recognise that we are building an infrastructure to serve as insurance against a low probability, high impact event. To justify developing this infrastructure in the face of other needs, I strive to ensure that our preparation for the hypothetical is simultaneously applicable to the real. My intention is for our infrastructure-cuminsurance policy to serve double duty today and to be useful in the future, even if our worst fears are never realised.

In our planning, we have emphasised three traditional public health functions: education, surveillance, and control. Public education is crucial for quelling panic, and to support rationing or limits on civil liberties that may need to be imposed. Educating the medical community can be the most direct way to get information about an emerging health threat quickly to local providers who might not have access to official federal and state government releases. Thus, even though funding is long gone for the sort of successful educational campaigns that we mounted against smoking and to promote HIV testing, at least our current public health emergency planning outreach capacity allows us to alert the community to occasional garden-variety disease outbreaks as well as to those of the hothouse sort should they ever occur.

Passive surveillance is the classic public health technique of receiving and evaluating disease reports. We also have an active surveillance component, consisting of daily data transfers to the health department from 11 acute care hospital emergency rooms and some large outpatient practices. The data are filtered into syndromes and statistical aberrations are investigated. The system is always operational, and has detected the onset of seasonal influenza, a pollen-induced asthma outbreak, and the "Clinton syndrome"-a spike in local emergency room visits for chest pain after Westchester's most distinguished resident underwent emergency coronary artery bypass surgery in 2004 .

Finally, though budgetary constraints preclude, for example, implementation of programmes to improve diet and to increase physical activity in the fight against obesity, we are actively controlling other present and future public health problems. Whether applying larvicide and eliminating standing water to control West Nile virus or laying the groundwork for involuntary isolation and quarantine with the local judiciary, medical community, and public safety officials, we are simultaneously practising public health, planning for public health emergencies, and developing public health infrastructure.

Tension remains between what we see and what we only imagine but fear deeply. History will judge whether today's public health paradigm is alarmist or apocalyptic, but regardless, we are doing what we can.

Joshua Lipsman Westchester County (New York) commissioner of health, USA jbl2@westchestergov.com
SOUNDINGS

\section{Three Bs, please}

"If you've got any grade As at A level you shouldn't be allowed to do medicine. All you get is the neurotics or the 'gifted' no-social-skills types. I would shoot all those sods on admission panels." $\mathrm{He}$ glanced at me, and I nodded my approval.

I like drunken conversations. The self congratulation, back slapping, and unquestioned certainty of new political manifestos-for a few hours the world does seem brighter-until reality shakes you awake demanding breakfast.

How should we choose medical students? Should we select the "brightest"? The qualities needed in medical practice are often completely opposite to those needed to get three As at A level. Having a personality obsessed with detail means you miss the bigger picture and leads to queues of patients boarding the anxiety rollercoaster of needless investigation. Also many of the "brightest" end up hating the job because they never wanted to do the glorified social work that is medicine.

The gift of the gab, blarney, patter, or a silver tongue are what we need. A willingness to accept uncertainty and the ability to reassure. To see the person and not refer, knowing that "health seeking behaviour," not illness, determines patients' use of the NHS. We need the judicious use of the "rubber ear": ignoring spurious symptoms of frequent attendees who merely want to talk.

The A levels are out now and salivating admissions panels will take the usual cream of the crop. Should we shoot the admissions panels in a Stalinis purge and impose a panel of "workers" instead, marking down potential students who play a classical instrument, rejecting all those with Duke of Edinburgh awards, and burning all the applications from the puffed up private schools? Well probably not, for the attributes of a doctor have nothing to do with social class, nor whether your parents suffered the misery of paying for your education. But perhaps it is time for a rethink.

For admissions panels I have a few suggestions. More mature students (early 20 s, ideally), more students from the allied professions, and-most importantly-more students with lower grades, which might see an increase from the state sector. Go easy on the "gifted," for all our sakes. Finally, admissions panels need more plodding, jobbing consultants and general practitioners who might spot the gems interested in people and service.

Des Spence general practitioner, Glasgow 